\title{
O Trabalho de Colaboradores com Deficiência nas Empresas: com a Voz os Gestores de Recursos Humanos ${ }^{1}$

\author{
The Work of Employees With Disabilities in Companies: the Perspective \\ of HUMAN RESOURCE MANAGERS
}

\author{
Kátia Soares COUTINHO ${ }^{2}$ \\ Graciela Fagundes RODRIGUES ${ }^{3}$ \\ Liliana Maria PASSERINO ${ }^{4}$
}

\begin{abstract}
RESUMO: o protagonismo da pessoa com deficiência tem marcado o espaço escolar, a universidade e o mercado de trabalho, apesar do país ainda ter um longo caminho a ser percorrido. Uma das estratégias para minimizar visóes reducionistas que levam em conta apenas o que falta na pessoa com deficiência são as políticas de açôes afirmativas que emergem no Brasil a partir dos anos 90. Os dispositivos legais brasileiros e a fiscalização de seu cumprimento pressionam os setores de Recursos Humanos $(\mathrm{RH})$ das empresas a incorporar projetos inclusivos que propiciem a contratação de colaboradores com deficiência. O artigo apresenta um recorte de uma pesquisa que se propôs a descrever as representaçóes de gerentes de RH sobre o trabalho da pessoa com deficiência. Caracteriza-se como um estudo de caso (multicasos), desenvolvido a partir de observações não participantes e entrevistas semiestruturadas com sete gerentes de RH de empresas brasileiras de grande porte. Os resultados revelam que a constituição de preconceitos em relação à pessoa com deficiência contribui para que ela seja percebida como a responsável pelas limitaçóes advindas dessa condição, omitindo-se fatores provenientes de um contexto social que não assume, ainda, a inclusão como compromisso em todos os âmbitos.
\end{abstract}

PALAVRAS-CHAVE: Educação Especial. Gestor. Mercado de Trabalho. Pessoa com Deficiência.

\begin{abstract}
The protagonism of persons with disabilities has characterized the school setting, the universities and the labor market, even though the country still has a long way ahead. One strategy to minimize reductionist views that take into account only what lacks in persons with disabilities are affirmative policies emerging in Brazil since the nineties. Brazilian legal provisions and supervision pressure the Human Resources (HR) departments of companies into incorporating projects of inclusion that enable hiring employees with disabilities. This paper presents part of one research with the purpose of recognizing representations of HR managers about the work of persons with disabilities. It is characterized as a case study (multi-case), conducted through observations and semi-structured interviews with seven HR managers from large Brazilian companies. Results reveal that development of prejudice towards persons with disabilities causes them to be perceived as responsible for the limitations that result from their condition, omitting factors from a social context that still does not commit to inclusion in all levels.
\end{abstract}

KEYWORDS: Special Education. Manager. Labor Market. Person with Disability.

\section{INTRODUÇÃo}

O trabalho constitui um dos aspectos mais importantes para a formação da identidade do homem como um ser social, e na atualidade, as organizaçóes produtivas estáo procurando incorporar cada vez mais a diversidade para compor suas forças de trabalho (TORRES; PÉREZNEBRA, 2014). Levando em conta esse aspecto, os dispositivos legais brasileiros - e a fiscaliza-

\footnotetext{
${ }^{1}$ http://dx.doi.org/10.1590/S1413-65382317000200008

${ }^{2}$ Doutoranda em Informática na Educação, Programa de Pós-Graduação em Informática na Educação, Universidade Federal do Rio Grande do Sul. Porto Alegre, RS, Brasil. katias_coutinho@hotmail.com

${ }^{3}$ Doutoranda em Educação, Programa de Pós-Graduação em Educação, Universidade Federal do Rio Grande do Sul. Porto Alegre, RS, Brasil. gracifrodrigues@gmail.com

${ }^{4}$ Docente da Faculdade de Educação, do Programa de Pós-Graduação em Educação e do Programa de Pós-Graduação em Informática na Educação, Universidade Federal do Rio Grande do Sul. Porto Alegre, RS, Brasil. liliana@cinted.ufrgs.br
} 
ção de seu cumprimento - pressionam os setores de Recursos Humanos (RH) das empresas a incorporar projetos inclusivos que propiciem a contratação de colaboradores com deficiência. Tal compromisso, imbuído em uma realidade muitas vezes adversa, perpassada por dificuldades contextuais próprias da realidade histórica e social da atividade laboral brasileira percebida através de indicadores econômicos: enquanto o percentual de empregabilidade das pessoas com deficiência (PCD) no mercado formal em países desenvolvidos gira entre 30\% e 45\%, no Brasil este indicador fica em torno de apenas 2\% (MENDONÇA, 2010). Este panorama apresenta-se mais inquietante se verificarmos a taxa de empregos formais no Brasil, a partir da Relação Anual de Informaçóes Sociais (Rais), ano base $2015^{5}$, que revela 47.657.552 trabalhadores sem deficiência ao lado de um quantitativo de 403.255 trabalhadores com deficiência. Verifica-se, que a taxa de PCD com emprego formal aproxima-se a 1\% segundo a Rais (2015). Apesar de este índice ser muito reduzido, se compararmos aos anos anteriores, 2013 e 2014, constatamos que há um discreto aumento, como por exemplo: em 2013 foram 357.797 e 2014381.322 o número de trabalhadores com deficiência com vínculo formal de trabalho. Ou seja, a cada ano há um acréscimo no número de PCD e reabilitados no mercado formal de trabalho. No recorte de tipologia de deficiência, a partir da Rais (ano base 2015) nos deparamos com o predomínio da deficiência física com o mais alto índice de vínculo formal de trabalho em todas as regióes brasileiras totalizando 49,79\%, seguida da auditiva com $19,68 \%$ e da visual com $11,63 \%$.

A visão dos profissionais de RH acerca do trabalho da pessoa com deficiência foi investigada por Tanaka e Manzini (2005) na qual verificou-se a centralidade da legislação como propulsora para que as empresas contratem PCD. Os autores concluíram que tanto fatores intrínsecos (falta de escolaridade, de interesse e de preparação profissional e social) quanto extrínsecos (as empresas, as instituiçóes especiais e o governo) corroboram para as dificuldades nos processos inclusivos no âmbito laboral. Além disso, Araujo e Schmidt (2006) discutem as contradiçôes entre o que o mercado de trabalho espera das PCD e o que as instituiçóes educacionais realizam para que estas pessoas estejam aptas a ingressarem em atividades laborais, sendo que, por parte das empresas investigadas no estudo, os dois empecilhos para o não cumprimento da Lei de Cotas são a baixa escolaridade e qualificação profissional das PCD. Por outro lado, as instituiçóes afirmam que as empresas adotam processos de contratação inadequados como a "falta de tolerância, solidariedade e paciência das empresas para com a PNE [pessoa com necessidades especiais]" (ARAUJO; SCHMIDT, 2006, p. 253).

No âmbito específico das PCD intelectual e as concepçóes de gestores acerca da sua atuação no trabalho, as contribuiçóes de Silva (2014) consideram que a diminuição da segregação social passa pela via do trabalho e que o conhecimento e a experiência com o público-alvo estudado, a partir dos gestores participantes, mostraram-se incipientes, o que indica, segundo a autora, fatores limitantes às possibilidades de desenvolvimento deste público. Esta constatação irá revelar-se no processo de contratação de PCD, que foi objeto de estudo da pesquisa de Lorenzo (2016) que, em análise desse processo para o mercado formal de trabalho de empresas de um município do interior paulista percebeu o predomínio dos fatores limitantes oriundos dos tipos de deficiência expressos pelos profissionais do RH participantes, além das dificuldades de preparo profissional associado ao conhecimento das legislaçóes referentes às políticas de açóes afirmativas. Somam-se a isso, os dados mencionados nos estudos acima em relação aos

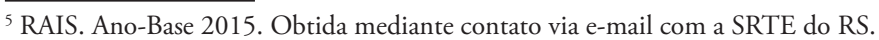


desafios da inclusão da PCD no mercado de trabalho como, por exemplo, a centralidade da Lei de Cotas como fator representativo para esta contratação; a tipologia da deficiência como critério para a ocupação de determinados postos de trabalho e a formação e qualificação profissional tanto da pessoa com deficiência quanto dos profissionais implicados na contratação nas empresas. Com isso, o presente trabalho se embasa na premissa de que todo processo inclusivo, seja este educacional, social ou laboral precisa partir de uma apropriação do contexto sociocultural dos diferentes atores envolvidos (empregadores, PCD e empresa).

Esta investigação, de cunho qualitativo, buscou compreender as representações que os gerentes de RH têm sobre o trabalho da pessoa com deficiência. Que dificuldades são percebidas? Quais são os aspectos positivos percebidos pelas empresas com a contratação de colaboradores com deficiência? Que elementos exercem influência sobre os processos inclusivos? Assim, o artigo organiza-se destacando o papel da Educação Profissional no atual contexto brasileiro como uma das promotoras da inclusão laboral de PCD. Na sequência, são evidenciados os principais dispositivos legais vigentes no Brasil e que possuem relação com o ingresso de PCD no âmbito laboral associados, na continuação, com a abordagem social acerca do que se considera deficiência. E, por fim, o contexto empírico da pesquisa é resgatado através de excertos provenientes das entrevistas realizadas delineando, então, um panorama de como tem sido representado o trabalho de colaboradores com deficiência nas empresas e quais recursos de acessibilidade e adaptaçóes já estão presentes, a partir da voz dos gestores de RH.

\section{EdUCAÇÁO PROFISSIONAL E TRABALHO: INTERFACES COM A INCLUSÁO DE PESSOAS COM DEFICIÊNCIA}

Abordar a inclusão para além do acesso à escola implica visualizar que a abrangência do conceito repercute em várias esferas da sociedade nas quais as PCD possuem direito de participação como qualquer cidadão. Direito de ir e vir, de estudar, de trabalhar, etc. E um desses direitos - de acesso ao trabalho -, em algumas situaçóes, é viabilizado por meio de cursos profissionalizantes promovidos por diferentes organizaçóes não governamentais e, no caso do Brasil, acrescenta-se o sistema "S", formado pelo Serviço Nacional de Aprendizagem Industrial (SENAI), Serviço Nacional de Aprendizagem Comercial (SENAC), Serviço Social da Indústria (SESI), Serviço Social do Comércio (SESC), Serviço Social de Transporte (SEST), Serviço Nacional de Aprendizagem do Transporte (SENAT), Serviço Nacional de Aprendizagem Agrícola (SENAR), Serviço Brasileiro de Apoio à Micro e Pequenas Empresas (SEBRAE) e Serviço Nacional de Aprendizagem do Cooperativismo (SESCOOP). Esse sistema integra o maior do país em termos de atuação no campo da Educação Profissional (EP), em seus diferentes níveis: qualificação básica, educação técnica e tecnológica (GRABOWSKI; RIBEIRO, 2010).

Em relação à inserção no mercado de trabalho, o governo prevê, entre outras medidas, cursos de qualificação profissional. O Programa Nacional de Acesso ao Ensino Técnico e Emprego (Pronatec) é um programa articulado com vários Ministérios (Educação, Trabalho, Desenvolvimento Social e Agrário) e estabelece como um de seus públicos prioritários as pessoas beneficiárias dos programas federais de transferência de renda ${ }^{6}$. Uma das metas do Pronatec é a qualificação profissional de seus beneficiários, associada à tentativa de que a transferência

${ }^{6}$ No Artigo $2^{\circ}$ da Lei no 12.513/2011, incisos I, II, III e IV, encontra-se o detalhamento da população prioritária do Pronatec. 
de renda seja transitória. No período, 2011 a 2015, o Pronatec atingiu 9,4 milhóes de matrículas, $38 \%$ em cursos técnicos $62 \%$ em cursos de qualificação profissional ${ }^{7}$. No entanto este programa, a partir de 2017, ganha outros contornos em relação a sua proposta inicial, pois sua ênfase estará direcionada aos alunos do Ensino Médio de escolas públicas que realizarão cursos técnicos concomitantes, com duração de um a dois anos e meio. Trata-se do MedioTec, o qual sua abrangência serão alunos cursando o ensino médio, sendo que os cursos serão ofertados a partir da demanda do mercado de trabalho de cada regiáo.

A interface da EP com a Educação Especial nos remete às legislações dos anos 1990, contemplada no Decreto 3.298/1999, em seu Capítulo VII "Da Equiparação de Oportunidades", Art. 15: "Os órgãos e as entidades da Administração Pública Federal prestarão direta ou indiretamente à pessoa portadora de deficiência os seguintes serviços: II- Formação profissional e qualificação para o trabalho" (BRASIL, 1999). Sublinha-se, também, a Seção II "Do Acesso à Educação" que, no Art. 28, parágrafo 1, menciona os níveis dos cursos de EP: " $\$ 1^{\circ}$ A educação profissional para a pessoa portadora de deficiência será oferecida nos níveis básico, técnico e tecnológico, em escola regular, em instituições especializadas e nos ambientes de trabalho" (BRASIL, 1999).

No Plano Nacional de Educação (PNE 2014-2024) ${ }^{8}$ a EP ganha notoriedade em duas Metas (10 e 11). A Meta 10 corresponde à "Educação de jovens e adultos nos ensinos fundamental e médio, na forma integrada à educação profissional”, para a qual é proposta a oferta mínima de 20\% das matrículas para essa condição. Na Meta 11, "Educação profissional técnica de nível médio" fica evidente a prerrogativa de que as matrículas da Educação Profissional Técnica de nível médio devem triplicar, assegurando a qualidade da oferta e, pelo menos, 50\% da expansão no segmento público. Eis o desafio para reverter os índices acima, levando em consideração a prevalência das instituições privadas na oferta da EP no Brasil.

Outro aspecto é que a inclusão laboral relaciona-se com os processos escolares pregressos, o que significa que, por muitas décadas, esse acesso não era para todos, dentre eles para PCD. Tal cenário vem se modificando e hoje se observa a Educação como um direito inegável a todos. Assim, a EP obtém visibilidade no que tange a formação para o trabalho, seja em nível técnico ou então, de qualificação profissional básica. Ressalta-se que fragilidades na formação escolar repercutem nas possibilidades que PCD têm de ocupar determinados postos de trabalho, e consequentemente, nos salários percebidos. Embora não deva existir nenhuma diferenciação salarial para as mesmas funçóes, ainda convivemos com tal cenário que dialoga tanto com as questóes de formação e qualificação das PCD quanto às desvantagens sociais e de oportunidades a que estão expostas (COUTINHO et al., 2017).

As políticas públicas, inegavelmente, têm avançado no sentido de criar movimentos dinâmicos, que busquem atender às fragilidades que se evidenciam nos processos sociais e econômicos do país. Isso tem reflexos na necessidade de serem cumpridas e avaliadas políticas públicas em diferentes áreas e setores de abrangência, tendo em vista que não é a carência de legislação o nosso maior desafio, mas sim sua implementação, considerando entre outras questôes, aspectos vinculados à educação que repercutem na inclusão laboral.

${ }^{7}$ Disponível em: <http://portal.mec.gov.br/component/content/article?id=34611>. Acesso em: 23 maio de 2017.

${ }^{8}$ Lei n ${ }^{\circ} 13.005$, de 25 de junho de 2014, que aprova o Plano Nacional de Educação (PNE) e dá outras providências. 
Em nossa época, tanto a globalização como a plena utilização das tecnologias da informação e da comunicação (TIC) reconfiguraram várias circunstâncias das relaçóes sociais que afetam a concepção da atividade laboral como um todo. Assim, o trabalho vem sofrendo contínuas e profundas reformulações tanto nos processos de produção, nas ofertas de serviços e produtos, quanto na estrutura organizacional das empresas. Pinto (2005) considera que o trabalho constitui um fenômeno da sociedade, mostrando as relaçóes dialéticas do processo produtivo que compóem a verdadeira identidade do ser humano (PINTO, 2005). Nessa perspectiva, “[...] o homem só trabalha para si quando o faz para a sociedade inteira” (PINTO, 2005, p. 21).

Portanto, o trabalho implica fatores econômicos mas, sobretudo, de reconhecimento identitário e social às pessoas que o executam. O sentimento de realização que o cumprimento das tarefas proporciona, bem como a independência e autonomia reafirmam a cidadania de quem consegue fazer parte do mundo produtivo, e constituem, ao mesmo tempo, uma necessidade e um direito de todos?

\section{Dispositivos LEgAIS VIGENTES NO BRASIL NO ÂMBITO TRABALHISTA}

As políticas públicas de ações afirmativas que emergem no Brasil a partir dos anos 90 visam atender às exigências de atenção à diversidade e aos direitos das PCD mundialmente reconhecidos e resultados de importantes conquistas do movimento político do setor. Em nosso país, esta repercussão se faz presente em diversos artigos da Constituição Federal, como o direito ao trabalho e a proibição de qualquer discriminação no tocante a salário e critérios de admissão do trabalhador com deficiência (Artigo 7). Um prenúncio do que, três anos depois, seria a chamada "Lei de Cotas" (Lei 8.213 de 1991). Açóes afirmativas não se associam a um contexto histórico isolado, assim como não se propóem a remediar, exclusivamente, um passado marcado por desigualdades vivenciado por grupos marginalizados. Concordamos com Piovesan (2008) ao afirmar que "[...] as açóes afirmativas devem ser compreendidas náo somente pelo prisma retrospectivo - no sentido de aliviar a carga de um passado discriminatório -, mas também prospectivo - no sentido de fomentar a transformação social, criando uma nova realidade" (PIOVESAN, 2008, p. 890).

Alguns exemplos de políticas públicas de açóes afirmativas em vigência no Brasil, que possuem relevante papel social com repercussões socioeconômicas importantes são a Lei 8.112/1990, que assegura, nos concursos públicos, até 20\% das vagas para PCD e a Lei $8.213 / 1991$, a Lei de Cotas, que dispóe percentuais de vagas para PCD nas empresas com mais de 100 funcionários, variando de $2 \%$ a $5 \%$, conforme o número total de empregados. Na sequência destas Leis, o Decreto Federal no. 3.298/1999 é que vai regulamentá-las e realçar tanto a questão do ingresso em concurso público, estabelecendo percentual mínimo para reserva de vagas para os mesmos, quanto as cotas para PCD nas empresas privadas. Como se pode observar, tanto o serviço público quanto o privado assumem compromissos referentes ao ingresso de PCD em seus espaços. Tal compromisso também foi enfatizado na Convenção Internacional dos Direitos das PCD da ONU de 2006, promulgada no Brasil pelo Decreto no 6.949/2009, com valor de emenda constitucional, no seu Artigo 27 “Trabalho e Emprego", que declara

\footnotetext{
${ }^{9}$ No Brasil, a Constituiçáo de 1988 , no artigo $6^{\circ}$, reconhece o trabalho enquanto um direito e do artigo $7^{\circ}$ ao $11^{\circ}$ estáo prescritos os principais direitos para os trabalhadores que atuam sob as leis brasileiras. Além da Constituição, a Consolidação das Leis Trabalhistas (CLT) regulamenta também as relaçōes de trabalho no Brasil.
} 
como princípio elementar, na introdução: "1. Os Estados Partes reconhecem o direito das PCD ao trabalho, em igualdade de oportunidades com as demais pessoas” (BRASIL, 2011, p. 53).

A Lei Brasileira de Inclusão da Pessoa com Deficiência (Estatuto da Pessoa com Deficiência) - Lei no 13.146/2015 é enfática ao estabelecer no seu Capítulo VI, "Do Direto ao Trabalho" (parágrafos 30 e 4o), que:

$\$ 3^{\circ}$ É vedada restrição ao trabalho da pessoa com deficiência e qualquer discriminação em razão de sua condição, inclusive nas etapas de recrutamento, seleção, contratação, admissão, exames admissional e periódico, permanência no emprego, ascensão profissional e reabilitação profissional, bem como exigência de aptidão plena. (BRASIL, 2015).

Iniciativa de relevante contribuição na alçada tanto do ensino profissionalizante quanto na inclusão laboral das PCD, é a Lei da Aprendizagem Profissional (prevista na CLT, Art. 428, alterada pela Lei n. 10.097/2000 e, posteriormente, pela Lei n. 11.180/2005), que prevê, no Art.18, o "contrato de aprendizagem". Este é o contrato de trabalho especial, ajustado por escrito e por prazo determinado, em que o empregador se compromete a assegurar ao maior de 14 e menor de 24 anos, inscrito em programa de aprendizagem formação técnico-profissional metódica, compatível com o seu desenvolvimento físico, moral e psicológico, e o aprendiz, a executar com zelo e diligência as tarefas necessárias a essa formação. O limite de idade não é atribuído quando se tratar de pessoa com deficiência (Art.18, $\$ 5^{\circ}$ ), assim como a comprovação da escolaridade não se limita à conclusão de alguma série/ano específico, e sim a "[...] considerar, sobretudo, as habilidades e competências relacionadas com a profissionalização" (BRASIL, 2005, Art.18, $\$ 6^{\circ}$ ). Outro fator a ser levado em conta na legislação brasileira no âmbito trabalhista articulado ao segmento de PCD, é o Benefício de Prestação Continuada da Assistência Social (BPC), que é individual, náo vitalício e intransferível, assegurando a transferência mensal de 1 salário mínimo ao idoso, com 65 anos ou mais, e à pessoa com deficiência, de qualquer idade. Os beneficiários devem comprovar não possuir meios de garantir o próprio sustento, nem tê-lo provido por sua família, através da comprovaçáo de renda mensal familiar per capita inferior a 1/4 (um quarto) do salário mínimo vigente. De acordo com dados do Ministério do Desenvolvimento Social e Combate à Fome (MDS) ${ }^{10}$, em 2016 (referência/março), foram pagos 4.276.577 Benefícios de Prestação Continuada no Brasil, dos quais 2.343.164 destinaram-se a PCD (4,89\%) e 1.933 .413 a idosos $(3,92)$. Em comparação com os dados de 2015 (referência/março), percebemos um acréscimo nas concessóes ( 33.880 benefícios a mais em 2016), pois em 2015, foram 4.242.697 benefícios pagos, dos quais 2.323.794 destinaram-se a PCD e 1.918.903 a idosos.

Autores como Torres e Pérez-Nebra (2014) apontam certo tensionamento existente entre as três principais políticas públicas voltadas à inclusão de colaboradores com deficiência: ou seja, enquanto o BPC propicia a "acomodaçáo" da pessoa com deficiência, que pode permanecer em casa, longe do mundo do trabalho, recebendo seu benefício, a Lei de Cotas e a Lei da Aprendizagem pressionam as empresas a contratarem trabalhadores com deficiência sob pena de serem multadas.

\footnotetext{
${ }^{10}$ Os dados apresentados foram coletados mediante pesquisa no site do próprio MDS <http://mds.gov.br/area-de-imprensa/dados>. Este Ministério passa a denominar-se Ministério do Desenvolvimento Social e Agrário (MDSA) a partir de 31 de agosto de 2016 quando assume a Presidência da República Michel Temer, após o Senado Federal aprovar o processo de impeachment e afastar a presidente Dilma Rousseff do cargo.
} 
[...] Algumas vezes se apresenta uma oportunidade de trabalho, o profissional é localizado no mercado, mas não demonstra interesse no trabalho, uma vez que a bolsa provida pelo Estado [BPC] é similar ou maior ao que é oferecido pela posição. Assim, os programas assistencialistas acabam por também prejudicar a entrada de PCDs no mercado de trabalho. (TORRES; PÉREZ-NEBRA, 2014, p. 536).

Até 2011, o BPC representava um obstáculo ao ingresso de PCD no âmbito do trabalho formal, pois uma vez sendo admitida, a pessoa com deficiência beneficiária do BPC, passava a tê-lo cancelado e, se desejasse requerê-lo deveria realizar todo o processo novamente inclusive a perícia médica. Tal situação não propiciava que ela e nem sua família encontrassem atrativos para que o sujeito ingressasse no mercado do trabalho, pois ganhar um salário mínimo mensal em uma condição de estabilidade traduz-se com maior segurança do que enfrentar um mercado de trabalho que, geralmente, paga o mesmo valor (um salário mínimo mensal) em uma condição de instabilidade. A partir de 2011, entra em vigor a Lei n. 12.470 que regulamenta alguns aspectos do BPC, dentre eles a possibilidade de que o benefício não seja extinto e sim suspenso durante a vigência de contrato formal de trabalho pelo prazo de no máximo 02 anos. Assim, consideramos que este aspecto trazido na legislação proporcionou um incremento importante na viabilidade da presença de pessoas com deficiência no mercado de trabalho.

Há também a obrigatoriedade do setor produtivo, juntamente com o "Sistema S" de estruturarem os Cursos para atender à Lei da Aprendizagem, contemplando as exigências legais quanto ao percentual de aprendizes, com ou sem deficiência, participantes dos mesmos. Muitas vezes além do não cumprimento das vagas para aprendizes com deficiência existe a dificuldade na formação das turmas e uso de adaptaçóes que proporcionem acessibilidade aos aprendizes.

\section{DEFICIÊNCIA: VISÃO SOCIAL E USO DE RECURSOS ADAPTATIVOS}

As pessoas com deficiência sofreram, no decorrer da história, diferentes formas de exclusão e isolamento. "Preconceitos que foram historicamente construídos, por meio das relaçóes que a sociedade estabeleceu e continua estabelecendo com aquele que ela considera imperfeito, diferente, estranho, desconhecido e incapaz" (TANAKA, 2007, p. 21). Sob a égide de uma visão médica da deficiência, a integração da pessoa era um comportamento esperado: o aluno ou o trabalhador com deficiência deveria adaptar-se ao meio do qual fazia parte. Atualmente, as práticas sociais inclusivas vêm se tornando cada vez mais presentes, trazendo visibilidade e empoderamento às pessoas com deficiência, embora estas possuam dificuldades tanto de natureza física, sensorial, intelectual, quanto comportamental, psicológica e social. Vygotsky (1997) salienta que a compensação da deficiência passa pela mediaçáo propiciada pelo contexto social: "[...] o desenvolvimento cultural é a esfera fundamental onde se torna possível a compensação da deficiência. Quando é impossível um desenvolvimento orgânico posterior, abre-se ilimitadamente o caminho do desenvolvimento cultural." (VYGOTSKY, 1997, p. 187).

Gardou (2011, p. 15) corrobora esta ideia ao afirmar que, em relação à pessoa com deficiência "[...] os contextos facilitadores atenuam as suas consequências, ao passo que os inibidores, pelo contrário, aumentam-nas". E é por esta via que surgem os caminhos alternativos e adaptativos ao desenvolvimento "[...] que tendem a compensar a deficiência e a introduzir uma nova ordem em todo o sistema de equilíbrio alterado" (VYGOTSKY, 1997, p. 187, tradução 
nossa). Quanto à mediação propiciada pelo contexto social mencionada por Vygotsky (1997), pode-se reportar ao conceito de Tecnologia Assistiva (TA), pois é ela que direciona alternativas para potencializar o desenvolvimento das pessoas com deficiência, associada à participação ativa de pares ou outras pessoas mais experientes (professores, profissionais, entre outros). A TA refere-se a uma área de conhecimento da qual participam serviços e recursos favorecedores da eliminação de barreiras arquitetônicas e funcionais vivenciadas por pessoas que, em virtude de quadros de deficiência (física, sensorial, intelectual) ou com mobilidade reduzida, enfrentam dificuldades no acesso aos ambientes e/ou na realização de atividades do cotidiano sejam de vida diária, lazer, educacionais e laborais.

Mais recentemente, a maneira como a deficiência é percebida, tanto pelos gestores quanto por colegas de trabalho, torna-se um elemento importante para a compreensão da dimensão da diversidade. Configura-se um modelo de interpretação da deficiência, que perde sua característica de atributo individual e passa a ser um fenômeno contingencial que procura ajustar o ambiente às necessidades das pessoas com deficiência, remodelando as açóes sociais e laborais.

De acordo com Carvalho-Freitas e Marques (2007) entende-se que o colaborador com deficiência, ao ser incluído na atividade produtiva, possa ser valorizado pelas suas potencialidades, e que a sociedade e as organizações precisam se ajustar para garantir a plena participação dessas pessoas. Tanaka (2007) destaca a necessidade de promover modificaçóes e/ ou adaptaçóes tanto na organização dos postos de trabalho disponíveis e na área administrativa quanto no ambiente físico, arquitetônico, social, funcional, e atitudinal das empresas. No entanto, Carvalho-Freitas e Marques (2007) apontam que, sendo esta uma matriz de interpretação recente, precisará de tempo para ser efetivamente incorporada aos processos sociais e laborais. Atualmente, esta articulação tem se configurado como um "[...] deslocamento da questão da diversidade como problema social para se transformar em um problema técnico a ser gerenciado como um recurso dentro das organizaçóes de trabalho, o que se denomina de gestão por diversidade" (CARVALHO-FREITAS; MARQUES, 2007, p. 72). Torres e PérezNebra (2014, p. 536) concordam e complementam: "[assim] observa-se um crescente movimento de organizaçóes no sentido de adotar programas de gestão da diversidade e, em menor grau, de inclusão como parte das suas estratégias organizacionais”. Embora esses dois conceitos, diversidade e inclusão, possuam certa semelhança, os autores salientam que a distinção entre os mesmos se dá na medida em que a diversidade se refere à composição da força de trabalho, ao passo que a inclusão diz respeito ao modo que as pessoas são tratadas e participam dos processos organizacionais (TORRES; PÉRES-NEBRA, 2014).

Em decorrência dessas novas e complexas relaçóes gerenciais que envolvem a inclusão, as empresas têm procurado adotar uma postura de aceitação da diversidade entre os seus colaboradores, procurando ao mesmo tempo incluir trabalhadores com deficiência.

\section{Procedimentos metodológicos dA PESQUisA}

Esta pesquisa integrou o Projeto SolAssist Biblioteca Virtual de Soluçóes Assistivas ${ }^{11}$, com o registro e aprovação da Comissão de Pesquisa e pelo Comitê de Ética em Pesquisa (CEP) da Universidade Federal do Rio Grande do Sul (UFRGS) e a assinatura do Termo de

\footnotetext{
${ }^{11}$ Projeto no. 21620, aprovado em 17/11/2011, pelo Comitê de Ética em Pesquisa da UFRGS.
} 
Consentimento Livre e Esclarecido por parte das instituições e seus profissionais, sendo garantido o anonimato tantos dos participantes quanto das instituiçóes.

As indagaçóes sobre as representaçóes que os gerentes de RH têm sobre a atividade laboral dos colaboradores com deficiência permearam a metodologia do estudo de caso (multicasos), que permitiu aos investigadores um aprofundamento em relação ao fenômeno (YIN, 2005). Para os primeiros contatos com os possíveis sujeitos, foi utilizada uma listagem de empresas disponíveis a partir de uma parceira com o Ministério do Trabalho e o Grupo de Pesquisa Tecnologia em Educação para Inclusão e Aprendizagem em Sociedade (TEIAS) da UFRGS. Posteriormente usou-se a técnica da Bola de Neve (BALDIN; MUNHOZ, 2011), na qual os próprios Sujeitos indicaram outros gerentes de RH para participar da investigação. $\mathrm{O}$ número de participantes ficou estabelecida em sete Gerentes de $\mathrm{RH}$ que tiveram interesse e disponibilidade em participar da pesquisa (quadro 1), todos do sexo feminino e com formação superior, com faixas etárias bastante diferentes, atuantes em empresas no Rio Grande do Sul. O perfil das empresas era bastante diversificado, desde prestadoras de serviço a indústrias, apresentando setores ou programas/projetos específicos de inclusão ou não. Porém, todas eram do setor privado e de grande porte (acima de 200 funcionários) além do comprometimento da Empresa quanto ao processo de inclusão, independente da fase em que se encontravam ou do cumprimento das cotas previstas na Lei.

Quadro 1 - Características dos Sujeitos (RH), Empresas e Presença de Ações Inclusivas.

\begin{tabular}{|c|c|c|c|c|c|}
\hline Nome & Sexo & Idade & $\begin{array}{l}\text { Formaçáo - cargo } \\
\text { tempo de atuaçáo }\end{array}$ & Tipo de empresa Local & Açóes inclusivas \\
\hline RH 1 & $\mathrm{~F}$ & $31-40$ & $\begin{array}{l}\text { Graduação em Psicologia (PUCRS) } \\
\text { Especialização em Liderança Estratégica de } \\
\text { Negócios e Pessoas (ESPM/RS). } \\
\text { Analista de Recursos Humanos } \\
\text { Atuação na área: } 5 \text { anos. } \\
\end{array}$ & $\begin{array}{l}\text { Comunicação } \\
\text { Serviços } \\
\text { Gráfica } \\
\text { Porto Alegre }\end{array}$ & Programa Integrar \\
\hline $\mathrm{RH} 2$ & $\mathrm{~F}$ & $31-40$ & $\begin{array}{l}\text { Graduação em Pedagogia - Professora de Séries } \\
\text { Iniciais e Orientadora Educacional (Centro } \\
\text { Universitário Ritter dos Reis). } \\
\text { Assistente de Projetos Sociais. Atuação na área: } \\
5 \text { anos. }\end{array}$ & $\begin{array}{l}\text { Medicamento } \\
\text { Loja } \\
\text { Indústria } \\
\text { Porto Alegre/ Eldorado do Sul }\end{array}$ & Programa Juntos \\
\hline RH 3 & $\mathrm{~F}$ & $31-40$ & $\begin{array}{l}\text { Graduação em Administração na FAPA.(em anda- } \\
\text { mento). Analista de Desenvolvimento Humano e } \\
\text { Organizacional. Atuação na área: } 3 \text { anos. }\end{array}$ & \begin{tabular}{|l|} 
Call Center \\
Telemarketing \\
Cobrança \\
Porto Alegre \\
(Sáo Paulo) \\
\end{tabular} & $\begin{array}{l}\text { Programa de In- } \\
\text { clusão da Empresa } \\
3 \text { (2009) }\end{array}$ \\
\hline RH 4 & $\mathrm{~F}$ & $51-60$ & $\begin{array}{l}\text { Graduação em Serviço Social. } \\
\text { Coordenaçấo do RH. Atuação na área: } 29 \text { anos }\end{array}$ & $\begin{array}{l}\text { Peças automotivas e industriais } \\
\text { (5 fábricas) } \\
\text { Gravataí }\end{array}$ & $\begin{array}{l}\text { Projeto de Inclusão } \\
\text { da Empresa } 4\end{array}$ \\
\hline RH 5 & $\mathrm{~F}$ & $20-30$ & $\begin{array}{l}\text { Graduação em Administração. Analista de Ad- } \\
\text { ministração Pessoal. Atuação na área: } 7 \text { anos. }\end{array}$ & $\begin{array}{l}\text { Peças automotivas } \\
\text { São Leopoldo }\end{array}$ & Não \\
\hline RH 6 & $\mathrm{~F}$ & $41-50$ & $\begin{array}{l}\text { Bacharel em Psicologia (UCS- Caxias do Sul). } \\
\text { Especialista em Gestão Estratégica (UFRGS). } \\
\text { Coordenadora de RH. Atuação na área: } 14 \text { anos. }\end{array}$ & $\begin{array}{l}\text { Indústria alimentícia } \\
\text { Canoas }\end{array}$ & Não \\
\hline RH 7 & $\mathrm{~F}$ & $31-40$ & $\begin{array}{l}\text { Graduação em Administração com ênfase em } \\
\text { Recursos Humanos (UNIASSELVI). Gestão de } \\
\text { Pessoas. Atuação na área: } 10 \text { anos. }\end{array}$ & $\begin{array}{l}\text { Indústria calçadista } \\
\text { Três Coroas }\end{array}$ & $\begin{array}{l}\text { Projeto Inclusão } \\
\text { Eficiente }\end{array}$ \\
\hline
\end{tabular}

Fonte: elaboração própria. 
Os dados foram coletados em duas etapas, no período de setembro de 2014 a outubro de 2015, a partir de observações in loco envolvendo questôes de acessibilidade e adaptações de postos de trabalho já presentes nas Empresas, e as condiçóes de acesso e transporte ao local. Entrevistas semiestruturadas foram gravadas nas próprias Empresas, com as sete gerentes do $\mathrm{RH}$, sendo posteriormente transcritas para análises. O foco recaiu sobre a atuação das gerentes de RH na gestão de colaboradores com deficiência, bem como a situação de cada uma das sete Empresas no âmbito dos processos inclusivos e a presença (ou não) de possíveis adaptaçóes em uso no ambiente de trabalho. As categorias que emergiram (MORAES, 2003) foram: dificuldades relacionadas ao nível educacional; adaptaçóes no ambiente laboral e falta de acessibilidade no entorno e os aspectos positivos da inclusão de colaboradores com deficiência. $\mathrm{Na}$ análise e discussão, item 6 a seguir, os sujeitos $(\mathrm{RH})$ foram identificados pelas legendas da primeira coluna do quadro 1 e as Empresas, pela letra inicial e número correspondente (quadro 1).

\section{As REPRESENTAÇÓES DOS GERENTES DE RH SOBRE O TRABALHO DA PESSOA COM DEFICIÊNCIA}

Conforme descrito nos procedimentos metodológicos, os dados provenientes da pesquisa de campo associaram-se aos aspectos educacionais, às adaptaçóes nos postos de trabalho e a acessibilidade do entorno e, por fim, aos fatores positivos manifestados pelas profissionais de $\mathrm{RH}$ acerca da inclusão de colaboradores com deficiência na empresa.

Entre as dificuldades para a efetivação da inclusão laboral, o desconhecimento dos empregadores em face da deficiência intelectual detectado na investigação de Lima e Jurdi (2014) em Santos/SP, é um aspecto corroborado por diversos autores, estendendo-se também às outras deficiências (COUTINHO, 2015; TANAKA, 2007):

O que é complicado é aceitar o diferente, o que não se conhece, o que não se sabe como lidar. ${ }^{12}$ (RH 2).

A passagem do paradigma da integração para a inclusão também é uma construçáo lenta e trabalhosa e a SRTE/RS destaca-se com um importante apoio nesta caminhada:

[...] ela [fiscal SRTE/RS] quer que a gente tenha uma cultura de inserção. [...] Eu acho que realmente não é um programa fácil. (RH 6).

E o papel da pessoa responsável pelo RH é o de gerir a diversidade e de implantar programas de inclusão como parte das estratégias das organizaçôes (CARVALHOFREITAS, 2004; TORRES; PÉREZ-NEBRA, 2014). Para atender a esta realidade, no programa já implantado na Empresa 4, há três projetos interligados e bem estruturados:

[...] temos o projeto intelectual, que é o Curso de Aprendizagem, o programa de sensibilização e recrutamento e tem o de acessibilidade, que são diferentes: uma coisa é tu ser uma Empresa acessível, outra coisa é tu ter a inclusão. O que a lei recomenda, então, quando construímos o

\footnotetext{
${ }^{12}$ Os excertos das falas das entrevistadas serão apresentados sem correção gramatical, em fonte menor e em itálico para se diferenciarem do corpo do texto.
} 
tripé, vimos que fechou direitinho: 'desenvolver um programa com ações visando que as pessoas com deficiência possam exercer seu direito ao trabalho, em igualdade de oportunidades com as demais pessoas, em ambientes acessíveis e seguros (RH 4).

\subsection{Dificuldades RELACIONADAS AO NÍVEL EDUCACIONAL}

As pesquisas apontam que $77 \%$ das ofertas de trabalho são operacionais, dispostas na base da pirâmide das organizaçóes, contra apenas $2 \%$ gerenciais, sendo o restante $21 \%$ de cargos técnicos (I.SOCIAL, 2012). Neste sentido, uma das Empresas que mais apresenta adaptaçōes, tecnologias e suporte à acessibilidade de seus colaboradores com deficiência, não consegue alcançar as cotas exigidas, pois o nível educacional exigido é mais alto. Na tentativa de diversificar suas fontes de recrutamento para conseguir profissionais qualificados, RH 1 cita o anúncio a seguir, veiculado em rádio FM, no qual se destaca a procura específica por colaboradores com deficiência por parte da Empresa 1:

[Empresa 1] valoriza as diferenças e acredita no seu potencial de desenvolvimento. Faça parte do Programa Integrar, destinado à inclusão de pessoas com deficiência. Mande seu currículo para [e-mail] ou através do telefone código de área 51 [no de telefone]..$^{13}$

Portanto, saindo do "chão da fábrica" onde os salários rivalizam com o BPC, nota-se que, quanto maior o nível de escolaridade exigido, mais difícil se torna encontrar profissionais com deficiência capacitados para serem contratados impedindo, assim, que a organização atinja as cotas previstas na legislação. Aqui apontamos a responsabilidade do sistema educacional como um todo nesse processo e também do ensino superior.

Dados acerca do nível de instrução da população brasileira a partir dos 15 anos oriundos do estudo de Gonçalves; Meletti; Santos (2015) com base no censo demográfico do IBGE/SIDRA (2010) revelaram que o índice de brasileiros com o ensino superior completo é de 9,3\%. No grupo de PCD, com ensino superior completo, os dados do Censo do IBGE 2010, indicam 6,7\%. Essa constatação sugere que há caminhos positivos na escolarização dessas pessoas nas etapas da Educaçáo Básica mais elevadas, indo além dos anos iniciais do Ensino Fundamental. Sobre o Ensino Superior, observamos que os índices estão aproximados, o que expóe que esse acesso vem sendo propiciado tanto a pessoas com e sem deficiência, embora ele ainda seja um nível educacional de pouco alcance.

Por outro lado, também existem muitas PCD que se empenham em procurar um espaço, uma oportunidade no mercado de trabalho, como aponta a RH 3:

[...] em compensação, tem gente muito bem qualificada. Ontem mesmo eu fiz uma entrevista com um deficiente visual formado em jornalismo e está fazendo curso de História, trabalha como jornalista e está querendo uma vaga como operador de cobrança. E a justificativa é que precisa de dinheiro para pagar a faculdade. ( $\mathrm{RH} 3$ ).

Garcia (2014) sinaliza o tímido acesso de PCD no mercado de trabalho formal, mesmo que haja em nosso País um "arcabouço jurídico adequado". Por isso, ao lado da análise das

${ }^{13}$ Anúncio veiculado na Rádio Itapema FM, prefixo 102.3, no período de julho/novembro de 2014. 
açóes afirmativas seja no âmbito laboral ou educacional existe a necessidade de olharmos para o par inclusão/exclusão social conjuntamente, a partir de um exame multidimensional.

O retorno tardio ou após longo período de afastamento ao disputado mercado de trabalho, como no caso dos colaboradores reabilitados, também modifica a forma da pessoa com deficiência se perceber como ser-no-mundo, (re)encontrando sua identidade profissional e elevando sua autoestima:

[...] Temos, por exemplo, uma bacharel em Direito que tem uma bolsinha de colostomia. Entrou de um jeito na Empresa [3], estava se sentindo a última das pessoas, estava há anos fora do mercado de trabalho [...] (RH 3).

A inclusão das PCD no mundo do trabalho possibilita tanto a conquista quanto o exercício de sua cidadania, bem como a percepçáo da sua capacidade profissional, amenizando preconceitos e estigmas que ainda estão presentes na sociedade. E, sem dúvida, a concretização de açóes políticas de inclusão laboral articulada às políticas educacionais pode amenizar a lacuna entre a qualificação do trabalhador com deficiência e o lugar que ele ocupa no mercado de trabalho.

\subsection{AdAPTAÇÓES NO AMBIENTE LABORAL E FALTA DE ACESSIBILIDADE NO ENTORNO}

A adaptaçáo dos postos de trabalho para que o colaborador com deficiência desempenhe suas atividades laborais de forma exitosa seria o correto, em um efetivo processo inclusivo, ou seja, focar no ser humano pensando primeiro na pessoa deveria ser prioritário, mas a matriz que aponta que a “[...] sociedade e as organizaçóes precisam se ajustar para garantir a plena participação dessas pessoas” (CARVALHO-FREITAS; MARQUES, 2007, p. 72) é recente e precisa de mais tempo para ser incorporada e sedimentada na cultura das organizaçóes produtivas. Em vista disso, a fala de uma das entrevistadas relata uma prática muito comum nas empresas:

[...] Nesse nosso projeto foi feito um mapeamento, então fica mais fácil para fazermos [...] esse projeto foi feito com a parte de engenharia de segurança e os médicos do trabalho, foram feitas fotos do setor e essa equipe mapeou quais são as funçóes que podem ser exercidas por PCD naquele setor. Lá na montagem, deficiência visual não conseguimos encaixar, mas conseguimos na TI [...]. Entáo esse mapeamento tem todos os cargos e definidos quais setores podemos colocá-lo (RH 7).

O panorama descrito nos revela a significativa importância do conhecimento e da promoção da acessibilidade em suas variadas dimensóes, pois até o momento, apesar dos avanços obtidos principalmente em termos legais, o que já é um passo muito importante, um dado que está presente ainda é que quanto menos desestabilizador para as empresas for a contratação de uma pessoa com deficiência, mais real e viável é sua efetivação.

A acessibilidade física detém a preferência da maioria das organizações, talvez por dar mais visibilidade e mostrar à comunidade que a empresa se preocupa com acessibilidade e inclusão. Isso evidencia uma restrição conceitual do que significa acessibilidade que permeia múltiplos aspectos (físico, comunicacional e atitudinal): 
[...] os projetos novos a gente já tem procurado fazer com acessibilidade para não precisar adequar [...] a expedição nova foi construída há uns três anos atrás, então ela já tem o banheiro adaptado, já tem a rampa [...] a portaria que tu comentaste é recente: dois anos para cá que a gente conseguiu adaptar ( $\mathrm{RH}$ 5).

$\mathrm{Na}$ empresa 4, um posto de trabalho foi adaptado para uma colaboradora com deficiência múltipla, ao serem oferecidas duas opçóes para a execução da tarefa para seu maior conforto: ela pode permanecer em pé ou sentada, sendo que a altura da mesa e da cadeira foram adequadas pelo médico e o engenheiro da Empresa à sua baixa estatura e postura diferenciada (ela tem problema na coluna, baixa visão e deficiência intelectual). De modo semelhante, os relatos de RH1 e RH 2 enfatizam a acessibilidade física das instalaçôes. Outra organização, porém, mostra uma solução que requer procedimentos diferenciados, em vez de equipamentos:

[...] Temos um menino [de 33 anos] que é autista que está no jurídico, ele tem problemas com horário... Ele é super inteligente, faz faculdade de administração, [...] é um menino que teria todo suporte, mas em função de morar sozinho ele chega muito atrasado, entáo fazemos um acompanhamento diário com ele: $9 \mathrm{~h}$, chamamos por e-mail, e logo ele responde 'estou aqui', é um acompanhamento full time. Na hora do almoço ele avisa que voltou [...] (RH 3).

Mas ainda há desconhecimento com relação às TAs, e a ajuda é limitada, evidenciando que a soluçáo tem que ser de baixo custo:

[...] às vezes, a pessoa não pode se abaixar, alguma caixa, algum peso. A gente teve um reabilitado agora há pouco que já era nosso funcionário, teve problema de coluna. Essas adaptaçóes: o colega que tá do lado faz, auxilia, pega de dupla. Esse tipo de adaptação é mais constante. (RH 5).

Assim, quando são sugeridas adaptaçóes onerosas e individualizadas, as Empresas não levam adiante a sua implantação, já que visam prioritariamente o lucro. É o exemplo da E3, cujo leitor de tela gratuito não é compatível com o sistema adotado, impedindo que colaboradores cegos trabalhem no setor:

[...] para mudar, além de ser muito caro, vai ter uma resistência muito grande dos clientes. (RH 3).

Quanto às dificuldades referentes aos meios de transporte, a RH 6 refere-se ao metrô de superfície:

[...] comecei a reparar em situaçóes do dia a dia que às vezes negligenciamos como, por exemplo, o Trensurb. O abrir e fechar de portas emite um sinal sonoro, porém para um DA [deficiente auditivo] ou surdo isso é inviável, reparei que até existem 2 sinais luminosos porém os mesmos não estão colocados acima das portas e sim na lateral do trem, o que se torna inviável para este tipo de deficiência. Seria uma boa medida reavaliar a identificaçáo dos trens. (RH 6, mensagem enviada via correio eletrônico). 
Com base no exposto, a presença crescente de PCD no mercado de trabalho ressalta a necessidade das empresas pensarem na acessibilidade das suas instalaçóes arquitetônicas para receberem esses colaboradores, entre outros fatores que possam facilitar a inclusão. Ademais, se verificarmos a taxa de empregos formais no Brasil, a partir da Relação Anual de Informaçóes Sociais (Rais), ano base 2015, no recorte de tipologia de deficiência nos deparamos com o predomínio da deficiência física com o mais alto índice de PCD com vínculo formal de trabalho em todas as regióes brasileiras. Ao nos depararmos com esses dados nos parece contraditório constatarmos que a deficiência física prevalece se comparada entre os outros tipos de deficiência nos empregos formais, sendo a acessibilidade um dos desafios constantes no cotidiano das PCD e ainda omitida em suas áreas de abrangência, como a comunicacional e a urbanística por exemplo.

\subsection{AsPECTOS POSITIVOS DA INCLUSÁO DE COLABORADORES COM DEFICIÊNCIA}

As empresas costumam perceber aspectos positivos com a inserção de PCD entre seus colaboradores. A maior estabilidade no emprego e o comprometimento no desempenho de suas funções são citados por Silva (2014), como características presentes nos colaboradores com deficiência intelectual. Além disso, a contratação dos mesmos "[...] melhora a imagem da organização perante os clientes e a imagem da organização perante os colaboradores, além de melhorar o clima da organização" (SILVA, 2014, p. 91). Em consonância com esses dados, RH 7 realizou um levantamento estatístico e verificou que o absenteísmo e a rotatividade dos dez colaboradores com deficiência, já contratados à época em que iniciou sua atividade na E7:

[...] não chegava a $1 \%$, enquanto no restante da fábrica girava em torno de $4 \%$ a $5 \%$. Ver que eles estão felizes com a oportunidade [de trabalhar]: ganham crachá da Empresa, uniforme, 'eu trabalho na [Empresa 7]' eles falam, a produção deles, a pontualidade, faltas, entấo, é praticamente zero [...] e, no final, tu vês o retorno que eles dão pra gente (RH 7).

Para o sucesso dos processos inclusivos, a legislação e sua efetiva fiscalização são tão importantes quanto às atitudes de acolhimento dos colegas e dos superiores do colaborador com deficiência. RH 3 afirma que sempre procura a cooperação dos gestores:

[...] sempre inserindo na cabeça do gestor que a Empresa precisa, que é importante para eles, que é uma chance que eles têm de evoluir como gestores, de desenvolver, trabalhar e trazer soluçóes para os problemas que vão surgir, é uma chance de evoluir pessoalmente (RH 3).

Por outro lado, para que os processos inclusivos em todas as instâncias se efetivem com êxito, "[...] a terminologia estigmatizante precisa dar lugar às palavras e noçóes que correspondem e remetem para o movimento geral, sem alienar a pessoa nas suas carências" (GARDOU, 2011, p. 16). Porém, tal movimento ainda é incipiente nos espaços laborais, e as gestoras entrevistadas utilizam corriqueiramente palavras que denotam o preconceito ao se referirem aos colegas com deficiência, pois a qualificação profissional das mesmas não contempla 
assuntos específicos tais como TA, adaptaçóes de postos de trabalho, recursos de acessibilidade e outros que facilitariam a inclusão, como assinala Lorenzo (2016):

Eu hoje não posso contratar cadeirante, muletante porque ele não vai ter acesso ao refeitório, por exemplo [...] membros superiores, máos e dedos, engloba tudo (RH 2).

No entanto, observa-se que a ascensão das PCD no mercado de trabalho formal e as possibilidades advindas deste meio não vêm acompanhadas, diretamente, de mudanças culturais. Gardou assinala que

[...] as nossas sociedades são animadas por dois movimentos divergentes: por um lado, uma febre de modernidade e de futuro, como na área das ciências, da técnica e da comunicação; por outro, uma resistência, até mesmo uma imobilidade nos arcaísmos, quando se trata do olhar que lançamos aos nossos pares em situaçáo de deficiência. (GARDOU, 2011, p. 14).

Essa dinâmica social a qual se refere o autor nos convoca a um deslocamento deste olhar de impossibilidades para outro de possibilidades, mas para isso é necessário vê-las muito além de pessoas merecedoras de caridade e assistencialismo.

\section{CONSIDERAÇóES FINAIS}

Os esforços das gerentes de RH tentam equacionar as variáveis envolvidas: por um lado, a falta de preparo/estudo formal do trabalhador com deficiência, o excesso de proteção familiar, o medo de perder o BPC, a carência generalizada de meios de transporte acessíveis, a presença de preconceito e a falta de atitudes inclusivas e de acolhimento e, por outro lado, as cobranças decorrentes da Lei de Cotas, que pressionam e afetam a contratação de funcionários com deficiência, pois seu cumprimento vem sendo fiscalizado anualmente pela Superintendência Regional do Trabalho e Emprego (SRTE).

Há, também, a necessidade de articulação com o Sistema $S$ para que sejam potencializados os ingressos de PCD nos diferentes cursos ofertados, atendendo não só à Lei da Aprendizagem Profissional, mas qualificando este grupo de pessoas para se inserirem no mercado de trabalho. Assim, a contratação de colaboradores com deficiência pode ser resultado de uma determinação legal, mas a sua permanência e suas possibilidades de avançar e contribuir de forma qualitativa e competitiva para o desenvolvimento da empresa dependerá de um trabalho estruturado de inclusão, acompanhamento e avaliação. Além disso, no caso de PCD, não é apenas a formação técnica que é fundamental, porém existe o contexto social (atividades de autocuidado, uso de ferramentas do ambiente, utilização de transporte coletivo, comportamentos na empresa, interaçóes interpessoais), que tem que ser analisado pelas instituiçóes formadoras, cujo foco precisa ir além da formação meramente técnica, apesar desta ser igualmente importante.

As dificuldades que se interpóem no dia-a-dia, como a prática de realizar mapeamento de atividades, efetivado pelos responsáveis pela segurança do trabalho (Empresas 5 e 7) muitas vezes mostram o desconhecimento de gestores quanto às possibilidades de uso de tecnologias assistivas, adaptaçóes das tarefas ou de postos de serviço, o que tornaria a atividade laboral possível para o colaborador com deficiência. A questão da segurança, apesar de necessária serve, muitas vezes como argumento para impedir esta inserção. Tal atividade deveria ser 
realizada por equipe multiprofissional, tentativa incipiente feita pela Empresa 7, cujo mapeamento envolveu, além da engenharia de segurança, também o médico do trabalho e RH 7.

Com isso, ao não serem viabilizadas estratégias que tornem acessíveis as atividades, sejam estas educacionais, laborais ou da vida diária, barreiras para o conhecimento e a aprendizagem são construídas, cotidianamente. Aponta-se a constituição de preconceitos na qual a pessoa com deficiência está sujeita por não conseguir realizar suas tarefas laborais, como se ela fosse responsável pelas limitaçóes advindas de sua condição. Omite-se os fatores provenientes de um contexto social que não assume, ainda, a acessibilidade como um compromisso em todos os âmbitos, percebendo-se ainda a existência do antigo paradigma da integração convivendo com o almejado processo de inclusão. No entanto, as profissionais de $\mathrm{RH}$, percebem pontos positivos decorrentes da inclusão de colaboradores com deficiência, destacando-se a diminuição da rotatividade e do absenteísmo bem como o incremento da produtividade, agregando um diferencial à Empresa: a melhoria da sua imagem junto à comunidade.

Se a história nos mostrou o descrédito no potencial das pessoas com algum tipo de deficiência, hoje, o que se apresenta é outra página dessa história. Deparamo-nos com a empregabilidade das PCD fomentada, ainda, principalmente pelo atendimento à Lei de Cotas. Melhor seria a não existência desse tipo de legislação, uma vez que todos nós temos o direito de acesso à saúde, à educação e, inclusive, ao trabalho, que é o meio pelo qual o ser humano se constitui como sujeito, capaz de produzir e sentir-se útil à sociedade.

\section{REFERÊNCIAS}

ARAUJO, J.P.; SCHMIDT, A. A Inclusão de pessoas com necessidades especiais no trabalho: a visão de empresas e de instituiçóes educacionais especiais na cidade de Curitiba. Revista Brasileira de Educação Especial, Marília, v.12, n.2, p.241-254, 2006. Disponível em: <http://www.scielo.br/pdf/ rbee/v12n2/a07v12n2.pdf>. Acesso em: 14 dez. 2016.

BALDIN, N.; MUNHOZ, E.M. Snowball (bola de neve): uma técnica metodológica para pesquisa em educação ambiental comunitária. In: CONGRESSO NACIONAL DE EDUCAÇÃO E 1º SEMINÁRIO INTERNACIONAL DE REPRESENTAÇÕES SOCIAIS, SUBJETIVIDADE E EDUCAÇÃO, 10., 2011, Curitiba. Anais... Curitiba, PR, 2011.

BRASIL. Convenção sobre os direitos das pessoas com deficiência. 4. ed. Brasília, DF: Presidência da República; Secretaria de Direitos Humanos; Secretaria Nacional de Promoção dos Direitos da Pessoa com Deficiência, 2011.

BRASIL. Decreto $n^{o}$. 3.298, de 20 de dezembro. Regulamenta a Lei no 7.853, de 24 de outubro de 1989, dispóe sobre a Política Nacional para a Integração da Pessoa Portadora de Deficiência, consolida as normas de proteção, e dá outras providências. 1999. Disponível em <https://www.planalto.gov.br/ ccivil_03/decreto/D3298.htm>. Acesso em: 30 out. 2016.

BRASIL. Lei no 11.180, de 23 de setembro. Institui o Projeto Escola de Fábrica, autoriza a concessão de bolsas de permanência a estudantes beneficiários do Programa Universidade para Todos PROUNI, institui o Programa de Educação Tutorial - PET, altera a Lei no 5.537, de 21 de novembro de 1968, e a Consolidação das Leis do Trabalho - CLT, aprovada pelo Decreto-Lei no 5.452, de 1o de maio de 1943, e dá outras providências. 2005. Disponível em: <http://www.planalto.gov.br/ ccivil_03/_Ato2004-2006/2005/Lei/L11180.htm\#art18>. Acesso em: 13 out. 2016. 
BRASIL. Lei no 13.146, de 6 de julho de 2015. Lei Brasileira de Inclusão da Pessoa com Deficiência (Estatuto da Pessoa com Deficiência). Presidência da República, Casa Civil. Brasília, DF, 2015.

BRASIL. Lei no 12.470, de 31 de agosto de 2011. Altera os arts. 20 e 21 e acrescenta o art. 21-A à Lei no 8.742, de 7 de dezembro de 1993 - Lei Orgânica de Assistência Social, para alterar regras do benefício de prestaçáo continuada da pessoa com deficiência. Disponível em: <http://www.planalto. gov.br/ccivil_03/_ato2011-2014/2011/lei/l12470.htm>. Acesso em: 30 maio 2017.

CARVALHO-FREITAS, M.N.; MARQUES, A.L. A diversidade através da história: a inserção no trabalho de pessoas com deficiência. Organizaçôes \& Sociedade, Salvador, v.14, n.41, p.59-78, 2007.

COUTINHO, B.G. et al. Qualidade de vida no trabalho de pessoas com deficiência física. Trabalho, Educação, Saúde, Rio de Janeiro, v.15, n.2, 2017.

COUTINHO, K.S. Biblioteca virtual de soluções assistivas: educação e trabalho. 2015. $201 \mathrm{f}$.

Dissertação (Mestrado em Educação) - Programa de Pós-Graduação em Educação, Faculdade de Educação, Universidade Federal do Rio Grande do Sul, Porto Alegre, 2015.

GARCIA, V.G. Panorama da inclusão das pessoas com deficiência no mercado de trabalho no Brasil. Trabalho, Educação, Saúde, Rio de Janeiro, v.2, n.1, p.165-187, 2014.

GARDOU, C. Pensar a deficiência numa perspectiva inclusiva. Revista Lusófona de Educação, Lisboa, n.19, p.13-23, 2011.

GONÇALVES, T.G.G.L.; MELETTI, S.M.F.; SANTOS, N.G. dos. Nível instrucional de pessoas com deficiência no Brasil. Crítica Educativa, Sorocaba, v.1, n.2, p.24-39, 2015.

GRABOWSKI, G.; RIBEIRO, J.A.R. Reforma, legislação e financiamento da educação profissional no Brasil. In: MOLL, J. (Org.). Educaçâo profissional e tecnológica no Brasil contemporâneo: desafios, tensóes e possibilidades. Porto Alegre: Artmed, 2010.

I.SOCIAL Soluçôes em Inclusão Social. Pessoas com deficiência: expectativas e percepçóes do mercado de trabalho. São Paulo, 2012.

LIMA, L.B. de; JURDI, A.P.S. Empregabilidade de pessoas com deficiência no município de Santos/ SP: mapeamento de políticas públicas e práticas institucionais. Revista Brasileira de Educação Especial, Marília, v.20, n.4, p.513-524, 2014.

LORENZO, S.M. de. Inserção de pessoas com deficiências no mercado formal de trabalho a partir da percepção dos profissionais de recursos humanos das empresas. 2016. 138f. Dissertação (Mestrado em Educação) - Faculdade de Filosofia e Ciências, Universidade Estadual Paulista, Marília, 2016.

MENDONÇA, L.E.A. de. Lei de cotas: pessoas com deficiência: a visão empresarial. São Paulo: LTr, 2010.

MORAES, R. Uma tempestade de luz: a compreensão possibilitada pela análise textual discursiva. Ciência \& Educação, Bauru, v.9, n.2, p.191-211, 2003.

PINTO, A.V. O Conceito de tecnologia. Rio de Janeiro: Contraponto, 2005. v.1.

PIOVESAN, F. Açôes afirmativas no Brasil: desafios e perspectivas. Revista Estudos Feministas, Florianópolis, v.16, n.3, p.887-896, 2008.

SILVA, K.S. As Concepçôes de gestores sobre a pessoa com deficiência intelectual e sua concepção no contexto laboral. 2014. 114f. Dissertação (Mestrado em Administração) - Faculdade de Ciências Empresariais, Universidade FUMEC, Belo Horizonte, 2014. 
TANAKA, E.D.O. Desenvolvimento de uma escala de atitudes sociais em relação ao trabalho da pessoa com deficiência. 2007. 198f. Tese (Doutorado em Educação) - Faculdade de Filosofia e Ciências, Universidade Estadual Paulista Júlio de Mesquita Filho, Marília, 2007.

TANAKA, E.D.O.; MANZINI, E.J. O que os empregadores pensam sobre o trabalho da pessoa com deficiência? Revista Brasileira de Educação Especial, Marília, v.11, n.2, p.273-294, 2005.

TORRES, C.V.; PÉRES-NEBRA, A.R. Diversidade e inclusão nas organizaçôes. In: ZANELLI, J. C., BORGES-ANDRADE, J. E.; BASTOS, A. V. B. (Org.). Psicologia, organizaçôes e trabalho no Brasil. 2. ed. Porto Alegre: Artmed, 2014.

VYGOTSKY, L.S. Obras escogidas: fundamentos de defectología. Tomo V. Madrid: Visor, 1997.

YIN, R. K. Estudo de caso: planejamento e método. 3. ed. Porto Alegre: Bookman, 2005.

Recebido em: 17/01/2017

Reformulado em: 01/05/2017

Aprovado em: 06/06/2017 